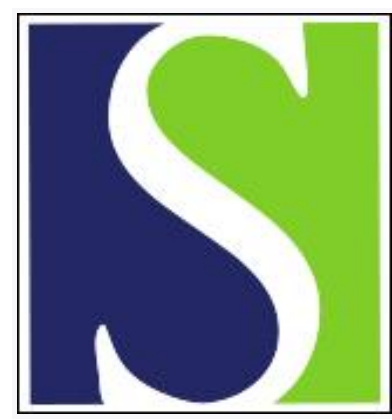

Scand J Work Environ Health 2004;30(6):486-496

https://doi.org/10.5271/sjweh.838

Issue date: Dec 2004

Annoyance and performance of three environmentally intolerant groups during experimental challenge with chemical odors

by Österberg K, Persson R, Karlson B, Ørbæk P

Affiliation: Department of Occupational and Environmental Medicine, Lund University Hospital, SE-221 85 Lund, Sweden. kai.osterberg@ymed.lu.se

Refers to the following texts of the Journal: $2000 ; 26(2): 93-98$ 2003;29(1):40-50 1999;25(6):569-573 1998;24(5):432-438 $2000 ; 26(3): 219-226 \quad 2003 ; 29(2): 143-151$

The following articles refer to this text: 2006;32(2):109-210; 2006;32(6):463-472

Key terms: annoyance; cacosmia; chemical odor; environmentally intolerant group; experimental challenge; exposure chamber; idiopathic environmental intolerance; performance; test performance

This article in PubMed: www.ncbi.nlm.nih.gov/pubmed/15633599 


\title{
Annoyance and performance of three environmentally intolerant groups during experimental challenge with chemical odors
}

\author{
by Kai Österberg, PhD, ${ }^{1}$ Roger Persson, PhD, ${ }^{1}$ Björn Karlson, PhD, ${ }^{1}$ Palle Ørbæk, MD ${ }^{1}$
}

\begin{abstract}
Österberg K, Persson R, Karlson B, Ørbæk P. Annoyance and performance of three environmentally intolerant groups during experimental challenge with chemical odors. Scand J Work Environ Health 2004;30(6):486-496.
\end{abstract}

\begin{abstract}
Objectives This study investigated exposure- and subject-related determinants of annoyance and performance during the chemical odor provocation of healthy persons with self-reported environmental annoyance.

Methods Persons with self-reported annoyance attributed to (i) chemicals or smells (smell-annoyed, SA, $\mathrm{N}=29$ ), (ii) electrical equipment (electrically annoyed, $\mathrm{EA}, \mathrm{N}=16$ ), and (iii) both smells and electricity (generally annoyed, $\mathrm{GA}, \mathrm{N}=39)$ were, together with referents $(\mathrm{N}=54)$, challenged with $n$-butyl acetate in an exposure chamber at levels far below the threshold values for neurotoxic effects and trigeminal irritation. A sequence of three air concentrations, $0.37,1.5$, and $6 \mathrm{ppm}\left(1.8,7.1\right.$, and $\left.28 \mathrm{mg} / \mathrm{m}^{3}\right)$ was used, counterbalanced within groups, together with intermittent periods of room air between each exposure level. The response measures comprised ratings of annoyance and smell intensity and reaction-time tests.

Results Only the GA group showed clearly elevated ratings of smell annoyance, mucous membrane irritation, and fatigue, as well as longer reaction times, compared with the referents, in response to the challenge. No group difference was found for the smell-intensity ratings. During intermittent periods without exposure, only the GA group maintained higher ratings for mucous membrane irritation and fatigue. Reaction time and all the rating dimensions showed a positive relationship with momentary n-butyl acetate concentration, while cumulative exposure had a more limited impact on the ratings and reaction time. A suggestion effect by the chamber environment before exposure could not be demonstrated.

Conclusions The results suggest that self-reported annoyance generalized to both electrical equipment and smells is a better predictor of chemical intolerance than self-reported annoyance to smells only.
\end{abstract}

Key terms cacosmia; exposure chamber; intolerance, idiopathic environmental; test performance.

During the last few decades, several environment-related syndromes have emerged in medical science. Some examples are multiple chemical sensitivity, hypersensitivity to electromagnetic fields, hypersensitivity to amalgam in dental fillings ("amalgamism"), the chronic fatigue syndrome, and the sick-building syndrome. A common denominator for these conditions is the nonspecific character of symptoms, including fatigue, headache, mental distress, irritation of the skin and mucous membranes, gastrointestinal complaints, and vertigo. Another common denominator is the lack of validated diagnostic methods in the absence of demonstrable pathogenic mechanisms (1). It has been observed that symptoms may exist even without a trigger present (2-4). At a World Health Organization (WHO) workshop in 1996, it was concluded that it would be appropriate to bring together the spectrum of medically unexplained disorders associated with environmental factors under the heading idiopathic environmental intolerance (IEI) (5). This step would seem logical, not only because of the overlap of symptoms $(6,7)$, but also because of observations indicating that sensitivity to one environmental factor often seems to coexist with sensitivity to several other environmental factors (8-10).

Recent hypotheses emphasize sustained high arousal and stress as crucial factors for the development of idiopathic environmental intolerance (11-13). Longterm overload or allostatic load $(14,15)$ is thought to put the organism in a state in which it is vulnerable to psychobiological sensitization. In the sensitized state, the organism reacts to specific triggers with an individually stereotypic, polysymptomatic stress response (16). Once annoyance has become linked to such trigger situations, the organism easily develops negative outcome

1 Division of Occupational and Environmental Medicine, Department of Laboratory Medicine, Lund University, Lund, Sweden.

Reprint requests to: Dr K Österberg, Department of Occupational and Environmental Medicine, Lund University Hospital, SE-221 85 Lund, Sweden. [E-mail: kai.osterberg@ymed.lu.se] 
expectancy, which may enhance the annoyance reaction (17) and reinforce the cognitive and attentive focus on triggers in order to escape such situations. Such mechanisms may explain why the annoyance reaction in cases of multiple chemical sensitivity does not fit a traditional neurotoxicologic dose-response relationship. Rather, it fits an "olfactory threshold model", in which cognitive-attentional processes elicit an annoyance response in a "none or all" fashion (18). Viewed from this perspective, a person's attribution of symptoms to some specific factor in the environment may be circumstantial (ie, it may be due to the particular sensory cues that were present in the environment at the time when symptoms began to emerge).

Earlier we had developed a challenge method for studying intolerance to chemical smells. Applying the method to clinical cases of multiple chemical sensitivity and chronic toxic encephalopathy $(4,19,20)$ resulted in a higher increase in ratings of fatigue and mucous membrane irritation during challenges in both clinical groups, when compared with age- and gender-matched referents. A main finding was that neither annoyance nor test performance showed a relationship to the contrasting neurotoxic properties of the two solvents used. This finding suggests that a neurotoxic effect on the central nervous system (CNS) is not the mechanism behind the intolerance reactions in multiple chemical sensitivity. However, since the exposure design used the same standardized, stepwise increase in air concentrations for all the participants, it was not possible to reliably discern effects of cumulative exposure from the effects of momentary air concentration. Another problem was that the people with multiple chemical sensitivity and those with toxic encephalopathy were clinical patients and had possibly entered into a "sick role". This situation may, in some respects, have biased the annoyance reporting and therefore limited the generalizability of results to a wider population of people experiencing a less disabling environmental intolerance.

In our present study, we applied a modified challenge design, using six different exposure sequences and intermittent periods without exposure, with persons recruited from the general population on the basis of selfreported annoyance to common environmental factors. The overall objective was to examine whether a unitary pattern of heightened reactions to one specific environmental trigger - chemical odor-would be found among different types of environmental intolerance. We aimed to determine whether it would be present not only among persons with self-reported intolerance to chemical smells, but also among those intolerant to electrical equipment. Moreover, we aimed to determine to what extent such reactions would be related to (i) basic suggestion or expectancy associated with the chamber environment before any contact was made with the odorant, (ii) the momentary air concentration of the odorant, and (iii) the cumulative exposure over time, and whether the reactions would linger during unexposed periods, following exposure.

\section{Study population and methods}

\section{Study population}

The subjects were previous respondents $(\mathrm{N}=13$ 381) to a questionnaire concerning illness prevalence and health care consumption, mailed to a representative sample $(\mathrm{N}=24922)$ of the population in the southernmost county of Sweden, Skåne (Scania). Details of the survey have been published elsewhere (21). The identification of people for our study was based on five questionnaire items. Three questions asked about recent annoyance related to electrical equipment, and two questions asked about recent annoyance related to smells: "During the past 14 days, did you experience annoyance that you associate with: (i) fluorescent tube lighting; (ii) visual display units; (iii) other electrical equipment; (iv) smells of chemicals; (v) other smells, and if so, how much annoyance did you experience?" The reply options were "no", "yes, some", or "yes, very much". Environmental annoyance was defined as a rating of the highest level of annoyance in at least one of the five questions. Altogether 315 persons were identified as meeting the criteria, after those above the age of 58 years and those who had reported long-term sick leave or disability pension in the initial population questionnaire were excluded. The mailed invitation also discouraged people with serious illness requiring medication (eg, diabetes, asthma, or psychiatric disorder) from participating. The 84 persons who completed the study were subclassified as (i) electrically annoyed (EA, N=16), reporting "very much" annoyance in relation to any of the items listed in questions 1-3 concerning electricity, but no annoyance produced by smells, as asked in questions 4-5; (ii) smellannoyed ( $\mathrm{SA}, \mathrm{N}=29$ ), reporting the highest level of annoyance with at least one of the items named in the questions concerning smells, but no annoyance concerning electricity; and (iii) generally annoyed ( $\mathrm{GA}, \mathrm{N}=39$ ), reporting the highest level of annoyance in either annoyance category, together with at least "some" annoyance in the other category. The reference group comprised 55 respondents to the population survey who denied having experienced annoyance in response to any of the items listed in all five questions, randomly selected to match the distribution of the age, gender, and socioeconomic status of the annoyance group (table 1).

The long-standing nature of environmental annoyance was validated by the Questionnaire on Chemical 


\section{Exposure chamber}

The exposure chamber had three solid walls and a glass front door. A stable primary air concentration was generated by a constant flow of air through a vessel containing the chemical, which was heated to a constant temperature. By using a combination of valves, we could dilute the primary mixture with further air to permit instantaneous alterations of the concentration. So that a final homogeneous mixture of room air and the chemical would be created, this mixture was led to a box below the chamber floor, containing winding channels. The final mixture entered the chamber through a $20-\mathrm{mm}$ wide slot along the entire rear side of the chamber floor. A slot $(0.57 \times 0.06 \mathrm{~m})$ in the center of the ceiling provided an outlet. The mixture was drawn into the chamber by the principle of underpressure, using a distantly placed fan connected to the outlet. The turnover rate was $145 /$ hour, corresponding to a mean air velocity in the chamber of $0.05 \mathrm{~m} / \mathrm{s}$. The chamber temperature ranged from $20.9^{\circ} \mathrm{C}$ to $26.6^{\circ} \mathrm{C}$, and the relative air humidity ranged from $21 \%$ to $38 \%$. The air concentration of the chemical was continuously monitored with an infrared spectrophotometer (Miran 1-A, Wilks Scientific Corp., South Norwalk, CT, USA), with the sampling nozzle in the approximate lateral center of the chamber, $0.4 \mathrm{~m}$ below the ceiling. Measurements of electrical and magnetic fields in the chamber showed that the levels did not exceed what is commonly found in apartments and office environments (details available on request). To ensure that the participants would not attribute annoyance to the electrical equipment surrounding the challenge chamber, we asked them to rate such attribution on the same type of response scale as used for smell annoyance during each phase. This rating showed that none of the groups were disturbed or provoked by the electrical equipment used (data not shown).

\section{Challenge design}

The exposure was not masked by any other odor because the intention was to provoke annoyance to the chemical odor as such. The provocation substance, n-butyl acetate $(\mathrm{BuAc})$, is strongly odorous at very low air concentrations. However, trigeminal irritation is not known to occur below 100 ppm (6 ppm was the maximum used in the challenge), and, due to its highly irritative effects on mucous membranes, no narcotic effects have been reported for humans at air concentrations that can be voluntarily sustained (ie, below 3000 ppm) (19). Each challenge session was divided into eight consecutive phases of 10 minutes' duration (figure 1). The initial phase (phase 0) was a "prechamber" phase in room air outside the chamber. After the participant entered the chamber, the chamber sequence started with a phase of room air. Next followed a phase with BuAc exposure, followed by another phase in room air. This pattern was repeated twice, giving three phases of BuAc exposure, each one being preceded and followed by a phase of room air. The air concentrations of BuAc used were $0.37 \mathrm{ppm}\left(1.8 \mathrm{mg} / \mathrm{m}^{3}\right), 1.5 \mathrm{ppm}\left(7.1 \mathrm{mg} / \mathrm{m}^{3}\right)$, and $6 \mathrm{ppm}$ $\left(28 \mathrm{mg} / \mathrm{m}^{3}\right)$. Typically, the air concentration stabilized within 3 minutes of each increase or decrease and varied less than $10 \%$ at each exposure level. The six possible permutations of BuAc sequence (0.37-1.5-6.0, $0.37-6.0-1.5,1.5-0.37-6.0,1.5-6.0-0.37,6.0-1.5-$ $0.37,6.0-0.37-1.5)$ was counterbalanced by the random assignment of each participant to one of the six sequences, and balancing was also carried out with respect to time of day (morning-afternoon) and gender. Towards the end of the data collection, specific exposure sequences were selected to obtain optimal final counterbalancing within the groups. The psychologist administering the challenge session was blinded to both the group membership and the exposure sequence of the participants.

\section{Challenge response}

In the chamber, the participant was seated comfortably in front of a small table top, facing the glass door. During each phase, the participant rated smell intensity and annoyance and completed two neurobehavioral performance tests. Response data were collected with the Eprime $^{\mathrm{TM}}$ test system (Psychology Software Tools, Inc, Pittsburgh, PA, USA). Stimuli were presented on a 15inch liquid crystal display (LCD) monitor, visible through the glass door, and were responded to on a simplified keyboard. Identical equipment outside the chamber served to familiarize the participants with the response procedures and to collect baseline data in the prechamber phase. Smell intensity was rated on the standardized 7-point category scale ranging from 0 to

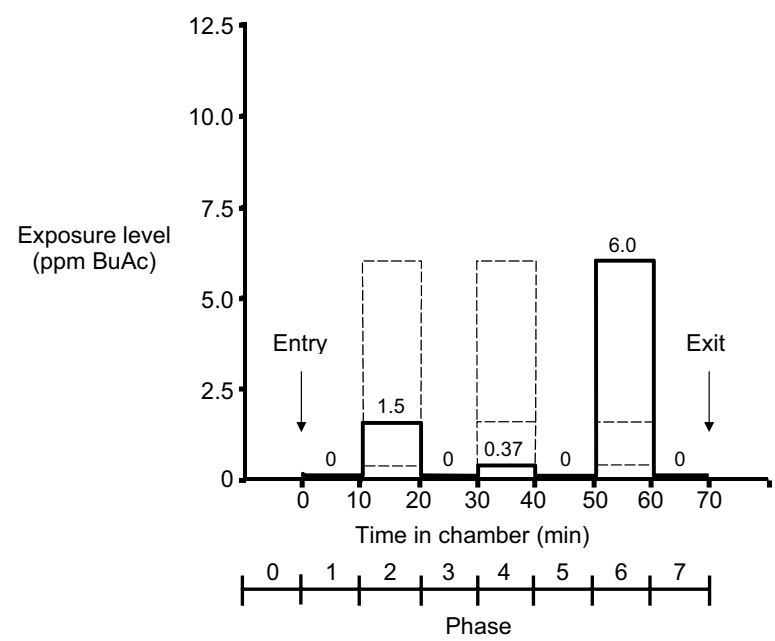

Figure 1. Phase duration and exposure levels during an exposure session with n-butyl acetate (BuAc)(exposure schedule, excluding the delay during exposure increase and decrease). 
6: none, very weak, weak, distinct, strong, very strong, extremely strong (27). Smell annoyance was rated on a 12-point Borg scale (28) with partial verbal anchorings, ranging from 0 (none) to 10 (extremely strong), including one decimal step of 0.5 (very, very weak). Perceived stress and strain was rated on a 5-point category scale ranging from 0 to 4: none, faint, some, much, very much. All other questions were rated on a visual analogue scale (VAS) (range 0-100) and were categorized into two indices due to high intercorrelations of single items: the items for irritation of the eyes, mouth or throat, and nose were averaged to give an index of mucous membrane irritation, and the ratings of drowsiness, headache, and concentration difficulties were averaged to give a fatigue index. The neurobehavioral performance tests were modified brief versions of two tests from the Automated Psychological Test System (29) used in our previous studies $(4,19)$, converted to the E-prime ${ }^{\mathrm{TM}}$ system. In the two-way reaction-time test (RT2), stimuli were white circles shown at the far left or right midline of the screen. The participants were instructed to place their index fingers on the two keys on the far left and right of a 5-key keyboard (the E-prime ${ }^{\mathrm{TM}}$ SRBox) and to respond as quickly as possible to each stimulus by pressing the button corresponding to stimulus laterality. Immediately following this was the inhibition reaction-time test (RT-inhib), in which the same visual stimuli were accompanied by simultaneous strong auditory signals at random intervals (ratio 0.50). The participants were instructed to avoid pressing a key when the white circle was accompanied by the auditory signal, while trying to maintain the habitual quick response to "silent" circles. Individual results were expressed as the mean of the $25 \mathrm{RT}$ responses, and in RT-inhib also as error ratio (ie, false hits).

\section{Operationalizations of the hypotheses}

Three issues were addressed. First, the possible expectancy or suggestion effects (ie, reactions evoked by merely entering the chamber environment were considered, studied by comparing ratings and test performance in the two initial phases without chemical exposure, that is, the prechamber phase and the first chamber phase). Second, the reactions to exposure to BuAc across the total chamber session were observed, studied as ratings and performance in response to, first, the momentary air concentration of BuAc (ie, a sensory-related reaction) and, second, the cumulative exposure to BuAc, during phases 2-7. The cumulative exposure level represented the total exposure to BuAc at the time of answering the questions in each phase, computed as the sum of products of every air concentration $(0.37,1.5$, and $6.0 \mathrm{ppm})$ and exposure duration, and expressed in ppm-minutes. The cumulative exposure at the time of answering the questions ranged from 0.8 ppm-minutes ( 2 minutes into phase 2 with $0.37 \mathrm{ppm}$ ) to $92.9 \mathrm{ppm}$-minutes (phase 7). Finally, the sustained annoyance during intermittent periods without exposure (ie, phases 3,5 , and 7, following each phase of BuAc exposure) were addressed, studied as the relationship between ratings and, on one hand, the air concentration of BuAc in the immediately preceding exposure phase (ie, remaining annoyance) and, on the other, the cumulative exposure to BuAc.

\section{Data analysis}

The general linear mixed models (MIXED) procedure in SPSS (version 11.5, SPSS Inc, Chicago, IL, USA) was used to specify a repeated-measures model. Categorical predictors were "group" (EA, SA, GA, and reference), "phase" (prechamber and first chamber), "BuAc air concentration" (0, 0.37, 1.5, and $6.0 \mathrm{ppm})$, and "BuAc air concentration in the previous phase" $(0.37,1.5$, and $6.0 \mathrm{ppm})$. The "cumulative exposure" was entered as a continuous predictor variable. Dependent variables were the scores of the rating scales and reaction-time tests. The models were solved using the restricted maximum likelihood (REML) method. Statistical inference for the mean structure of the data was made with fixed-effects models and approximate type III F-tests and t-tests.

The possible expectancy or suggestion effects were evaluated with a model involving the predictors "group" and "phase" and the interaction between the two.

The reactions to BuAc exposure across the total chamber session were evaluated with a model involving the predictors "group", "BuAc air concentration", and "cumulative exposure". To eliminate the impact of potential or known group differences in the baseline levels for the rating scales and neurobehavioral tests (see the Results section), defined as the respective level before any encounter with BuAc, we subtracted the score obtained in the first unexposed chamber phase for each rating or test variable from all subsequently obtained scores. For the purpose of finding differential patterns of reactions to chemical exposure across groups, the statistical modeling also included the two-way interactions "group by BuAc concentration" and "group by cumulative exposure".

Sustained annoyance during intermittent periods without exposure was evaluated with a model similar to the previous one, with the exception that "BuAc air concentration" was replaced by the predictor "BuAc air concentration in the phase immediately preceding the tested phase".

For all the analyses, an unstructured (UN), a firstorder autoregressive (AR1), and a compound symmetry (CS) covariance structure was tested, using Schwarz's Bayesian Criterion to guide the final selection. Residual 
plots were used to identify potential outliers and deviations from normality assumptions and problems with the distribution of variances. This procedure showed that all the variables satisfactorily complied with normality assumptions. P-values of $<0.05$ were considered statistically significant. Initially, all the factor terms were entered simultaneously, together with one interaction term at a time, and each interaction not reaching statistical significance was removed. Subsequently, the factor terms not showing statistical significance were also removed one at a time. For the final model, post-hoc testing was done with the estimate marginal means function and the parameter estimate function in the linear MIXED models procedure. In post-hoc testing, the EA, $\mathrm{SA}$, and GA groups were compared separately with the reference group.

The results have been typically expressed as the main effect (or interaction effect) P-value, followed by the post-hoc difference between the mean scores, with the $95 \%$ confidence interval $(95 \% \mathrm{CI})$, and, finally, the post-hoc P-value. Only statistically significant findings have been reported.

\section{Results}

\section{Rating scales}

Expectancy or suggestion effects during the first chamber phase. The ratings were generally low, and the changes in the ratings from the prechamber phase to the first chamber phase were not related to group. The statistically significant findings were as follows: (i) decreases in ratings across phases, irrespective of group, observed for smell intensity, with means declining from 0.55 to 0.34 (phase: $\mathrm{P}=0.014$; post hoc: $-0.21,95 \% \mathrm{CI}$ $-0.36-0.06, \mathrm{P}=0.007$ ) and mucous membrane irritation, with means declining from 15.6 to 11.6 (phase: $\mathrm{P}<0.001$; post hoc: $-4.0,95 \%$ CI $-5.8--2.2, \mathrm{P}<0.001$ ); (ii) group differences in overall ratings, irrespective of phase, as shown by higher mean ratings in the EA and GA groups, when compared with the reference group, for mucous membrane irritation (group: $\mathrm{P}=0.005$; post hoc for $\mathrm{EA}$ : 8.0, 95\% CI 0.6-15.5, $\mathrm{P}=0.034$; post hoc for GA: 9.1, 95\% CI 3.6-14.6, $\mathrm{P}=0.001$ ), fatigue (group: $\mathrm{P}=0.001$; post hoc for $\mathrm{EA}$ : 8.8, 95\% CI 1.7-15.8, $\mathrm{P}=0.016$; post hoc for $\mathrm{GA}$ : $12.3,95 \%$ CI $7.1-17.5, \mathrm{P}<0.001)$, and, in the GA group only when compared with the reference group, for smell annoyance (group: $\mathrm{P}=0.003$; post hoc: $0.26,95 \%$ CI 0.11 $0.42, \mathrm{P}=0.001$ ) and for stress and strain (group: $\mathrm{P}=0.003$; post hoc: $0.55,95 \%$ CI $0.24-0.87, \mathrm{P}=0.001)$.

Reactions to exposure to n-butyl acetate across the total chamber session. No group difference was found in the ratings of smell intensity. A strong relationship with BuAc concentration was found $(\mathrm{P}<0.001)$ (figure $2 \mathrm{a})$, and the ratings differed between all BuAc levels (post hoc: $\mathrm{P}<0.001$ throughout). A slightly negative relationship with cumulative exposure was observed, with lower intensity ratings at higher cumulative exposure $(\mathrm{P}=0.017$; beta $=$ $0.0025,95 \%$ CI $-0.0044--0.0005)$.

The ratings for smell annoyance were related to BuAc concentration $(\mathrm{P}<0.001)$ (figure $2 \mathrm{~b}$ ). They differed between all the BuAc concentrations (post hoc: $\mathrm{P}<0.001$ throughout; strongest difference for $0 \mathrm{ppm}$ versus 6.0 ppm: 3.3, 95\% CI 3.0-3.5). The SA and GA groups had a higher overall rating level (group: $\mathrm{P}<0.001$; post hoc for SA: 0.9, 95\% CI 0.4-1.4, P<0.001; post hoc for GA: 1.4, 95\% CI 1.0-1.9), P<0.001). Moreover, a higher reactivity to BuAc concentration was observed in the EA groups (BuAc concentration by group: $\mathrm{P}<0.001$ ), all three groups showing higher ratings at 6.0 ppm when compared with the reference group (post hoc for EA: 1.0, 95\% CI 0.1-1.9, $\mathrm{P}=0.026$; post hoc for $\mathrm{SA}$ : 1.3, 95\% CI 0.6-2.0, $\mathrm{P}<0.001$; post hoc for GA: 1.9, 95\% CI 1.3-2.6, $\mathrm{P}<0.001$ ), while, at 0.37 and $1.5 \mathrm{ppm}$, only the SA and GA groups had significantly higher ratings than the reference group, and no group difference was seen at $0 \mathrm{ppm}$.

The ratings for mucous membrane irritation were related to both of the exposure measures, but primarily to $\mathrm{BuAc}$ concentration $(\mathrm{P}<0.001$; post hoc for $0 \mathrm{ppm}$ versus 0.37 ppm: 1.9 , 95\% CI $0.3-3.4, \mathrm{P}=0.019$; post hoc for 0 ppm versus $1.5 \mathrm{ppm}$ : 3.9, 95\% CI 2.3-5.5, $\mathrm{P}<0.001$; post hoc for 0 ppm versus 6 ppm: $6.7,95 \% \mathrm{CI}$ $5.1-8.4, \mathrm{P}<0.001$ ) (figure $2 \mathrm{c}$ ). The $\mathrm{P}$-value for the main effect of cumulative exposure equaled 0.023 (beta $=0.021,95 \%$ CI 0.003-0.040). The GA group had higher overall ratings (group: $\mathrm{P}=0.002$; post hoc for $\mathrm{GA}$ : 8.0, 95\% CI 3.6-12.5, $\mathrm{P}<0.001)$.

The fatigue ratings were positively related to $\mathrm{BuAc}$ concentration $(\mathrm{P}<0.001)$, but only for $6 \mathrm{ppm}$ versus 0 ppm (post hoc: 2.9, 95\% CI 1.6-4.2, P<0.001) (figure $2 \mathrm{~d})$. Cumulative exposure had a relatively high impact on the fatigue ratings $(\mathrm{P}<0.001$; beta $=0.064,95 \% \mathrm{CI}$ $0.041-0.088$ ) (figure 3 ). The overall ratings were higher for the GA group than for the reference group (group: $\mathrm{P}<0.001$; post hoc for GA: 8.9, 95\% CI 5.4-12.4, $\mathrm{P}=0.001)$. An interaction effect was found for group by BuAc concentration $(\mathrm{P}=0.028)$, showing that only within the GA group were higher ratings given at both $1.5 \mathrm{ppm}$ and $6.0 \mathrm{ppm}$ (post hoc for $0 \mathrm{ppm}$ versus $1.5 \mathrm{ppm}$ : 3.0 , 95\% CI 1.0-4.9, $\mathrm{P}=0.003$; post hoc for 0 ppm versus 6 ppm: 5.7, 95\% CI 3.7-7.8, $\mathrm{P}<0.001)$. In the reference and EA groups, higher ratings were observed only at 6.0 ppm when compared with 0 ppm (post hoc for reference group: $1.9,95 \%$ CI $0.2-3.7, \mathrm{P}=0.031$; post hoc for SA: 2.5 , 95\% CI $0.1-4.8, \mathrm{P}=0.040$ ), while the ratings given within the $\mathrm{SA}$ group were unrelated to variations in BuAc concentration. 

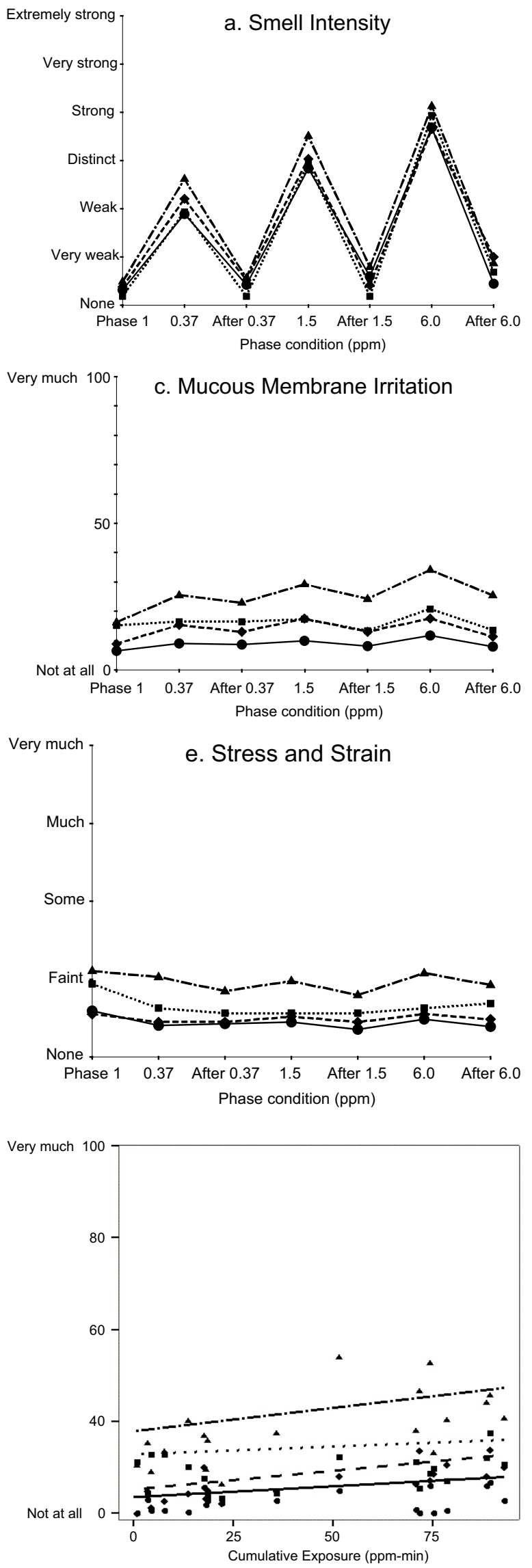
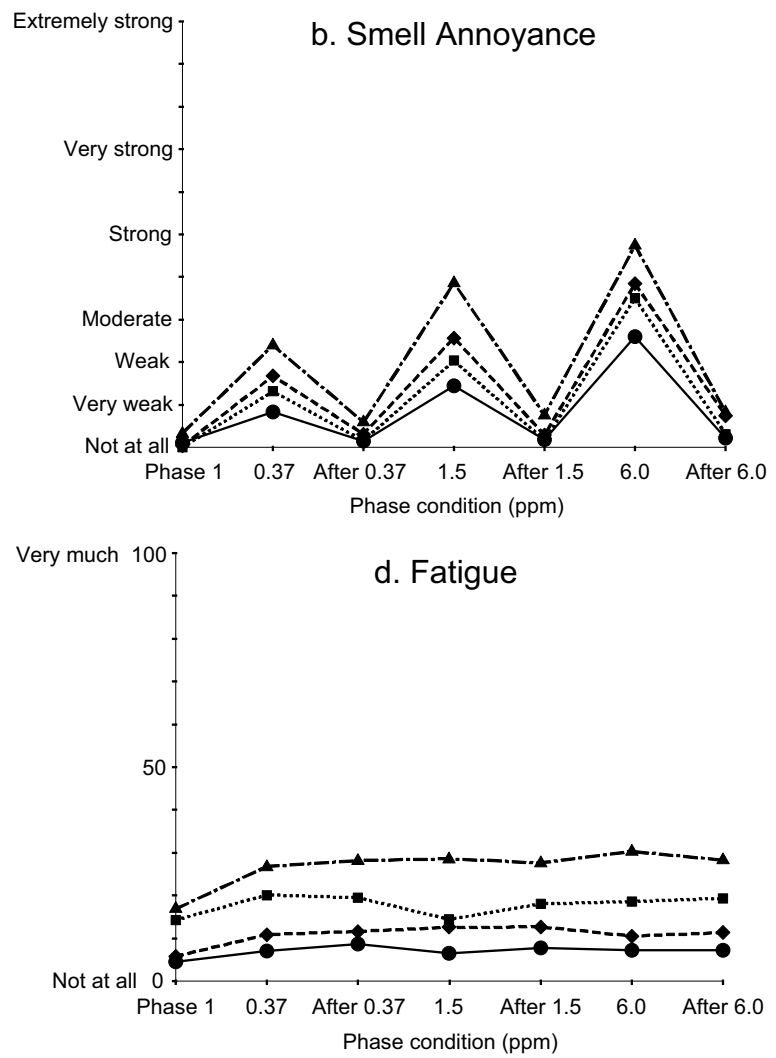

Figure 2. Ratings (means) of smell intensity (a), smell annoyance (b), mucous membrane irritation (c), fatigue (d), and stress and strain (e) during the first chamber phase, during 0.37-, 1.5- and 6.0-ppm exposure to n-butyl acetate, and during each following phase with 0-ppm exposure, given by electrically annoyed persons (dotted line with squares), smell annoyed persons (broken line with diamonds), generally annoyed persons (broken or dotted line with triangles), and referents (solid line with circles).

Figure 3. Relationships between fatigue ratings on a visual analogue scale and cumulative exposure for electrically annoyed (squares, dotted line), smell annoyed (diamonds, broken line), and generally annoyed (triangles, broken/dotted line) persons and the referents (circles, solid line). The markers show group means at each estimated level of cumulative exposure, and the lines indicate the resulting linear regressions. 
The stress and strain ratings were stable and even tended to decrease across the chamber phases (figure $2 \mathrm{e})$. They were affected only by BuAc concentration $(\mathrm{P}=0.002)$, showing a relatively small effect only at 6.0 ppm (post hoc for $0 \mathrm{ppm}$ versus $6 \mathrm{ppm}$ : $0.12,95 \% \mathrm{CI}$ $0.06-0.18, \mathrm{P}<0.001)$.

Reactions during intermittent periods without exposure. The ratings for smell intensity were generally very low during the nonexposure phases (figure 2a). A positive, statistically significant effect was found for BuAc concentration in the preceding phase $(\mathrm{P}<0.001)$. However, the observed interaction between group and the BuAc concentration of the preceding phase $(\mathrm{P}=0.002)$ proved this pattern to exist only in the annoyance groups and then only after the 6-ppm phase when compared with phases after lower concentrations $(0.37 \mathrm{ppm}$ versus 6.0 ppm for EA: $0.50,95 \%$ CI $0.10-0.89, \mathrm{P}=0.013 ; 0.37$ ppm versus $6.0 \mathrm{ppm}$ for SA: $0.48,95 \%$ CI $0.19-0.78$, $\mathrm{P}=0.001 ; 0.37 \mathrm{ppm}$ versus $6.0 \mathrm{ppm}$ for $\mathrm{GA}: 0.31,95 \%$ CI $0.055-0.560, \mathrm{P}=0.001 ; 1.5 \mathrm{ppm}$ versus $6 \mathrm{ppm}$ for EA: $0.50,95 \%$ CI $0.10-0.89, \mathrm{P}=0.013 ; 1.5 \mathrm{ppm}$ versus $6 \mathrm{ppm}$ for SA: $0.59,95 \%$ CI $0.29-0.88, \mathrm{P}<0.001 ; 1.5$ ppm versus 6 ppm for GA: not significant).

The ratings of the nonexposure phases were generally low for smell annoyance but related to the preceding BuAc concentration $(\mathrm{P}=0.007)$ (figure $2 \mathrm{~b}$ ). This finding indicates slightly higher smell annoyance ratings after the 6-ppm exposure when compared with those after the lower air concentrations (post hoc for $0.37 \mathrm{ppm}$ versus 6.0 ppm: $0.20,95 \%$ CI $0.07-0.30, \mathrm{P}=0.002$; post hoc for $1.5 \mathrm{ppm}$ versus $6.0 \mathrm{ppm}$ : $0.14,95 \%$ CI $0.02-$ $0.27, \mathrm{P}=0.027$ ).

The ratings for mucous membrane irritation were generally very low during the nonexposure phases (figure $2 c)$. They were only related to group $(\mathrm{P}=0.016)$, a finding indicating higher overall ratings than scored by the reference group in only the GA group (post hoc: 6.4, 95\% CI 2.0-10.8, $\mathrm{P}=0.016$ ).

For fatigue, the ratings were positively related to cumulative exposure $(\mathrm{P}<0.001$; beta $=0.058,95 \%$ CI 0.032 0.084 ), but negatively related to BuAc concentration in the preceding phase (figure $2 \mathrm{~d}$ ). In other words, a 6-ppm $\mathrm{BuAc}$ air concentration in the preceding phase resulted in lower fatigue ratings than the 0.37- or 1.5-ppm BuAc air concentrations in the preceding phase (post hoc for 0.37 ppm versus 6.0 ppm: $-1.7,95 \%$ CI $-3.3--1.0, \mathrm{P}=0.038$; post hoc for $1.5 \mathrm{ppm}$ versus $6.0 \mathrm{ppm}$ : $-1.9,95 \% \mathrm{CI}-3.4$ $-0.3, \mathrm{P}=0.016)$. A slight effect of group was also seen $(\mathrm{P}=0.044)$, indicating higher ratings in the GA group, both for GA compared with the reference group (post hoc: 7.3, 95\% CI 3.6-10.9, $\mathrm{P}<0.001)$ and for GA compared with the EA and SA groups $(\mathrm{P}<0.003)$.

No interaction or main effect was found for the stress and strain ratings (figure $2 \mathrm{e}$ ).

\section{Performance tests}

Expectancy or suggestion effects during the first chamber phase. No group difference was found for expectancy or suggestion effects during the first chamber phase. The statistically significant findings were an increase in RT2 reaction time (phase: $\mathrm{P}<0.001$; post hoc: $28 \mathrm{~ms}, 95 \%$ CI 23-34, P<0.001) and decreases in RTinhib reaction time and the error ratio score (phase for RT-inhib: $\mathrm{P}=0.011$; post hoc for RT-inhib: $-14 \mathrm{~ms}, 95 \%$ CI -25- -4, P=0.011; phase for RT-inhib error ratio: $\mathrm{P}<0.001$; post hoc for RT-inhib error ratio: $-3.2 \%, 95 \%$ $\mathrm{CI}-4.8--1.6, \mathrm{P}<0.001)$. The mean reaction times in the first chamber phase are shown in figure 4.

Reactions to exposure to $n$-butyl acetate across the total chamber session. BuAc concentration was positively related statistically significantly to RT2 reaction time (BuAc concentration: $\mathrm{P}=0.002$ ). However, this result was somewhat inconsistent since this relationship was found only for 0.37 - and 6.0-ppm exposures (post hoc for $0 \mathrm{ppm}$ versus $0.37 \mathrm{ppm}$ : $6.7 \mathrm{~ms}$, $95 \%$ CI 1.7-11.6,

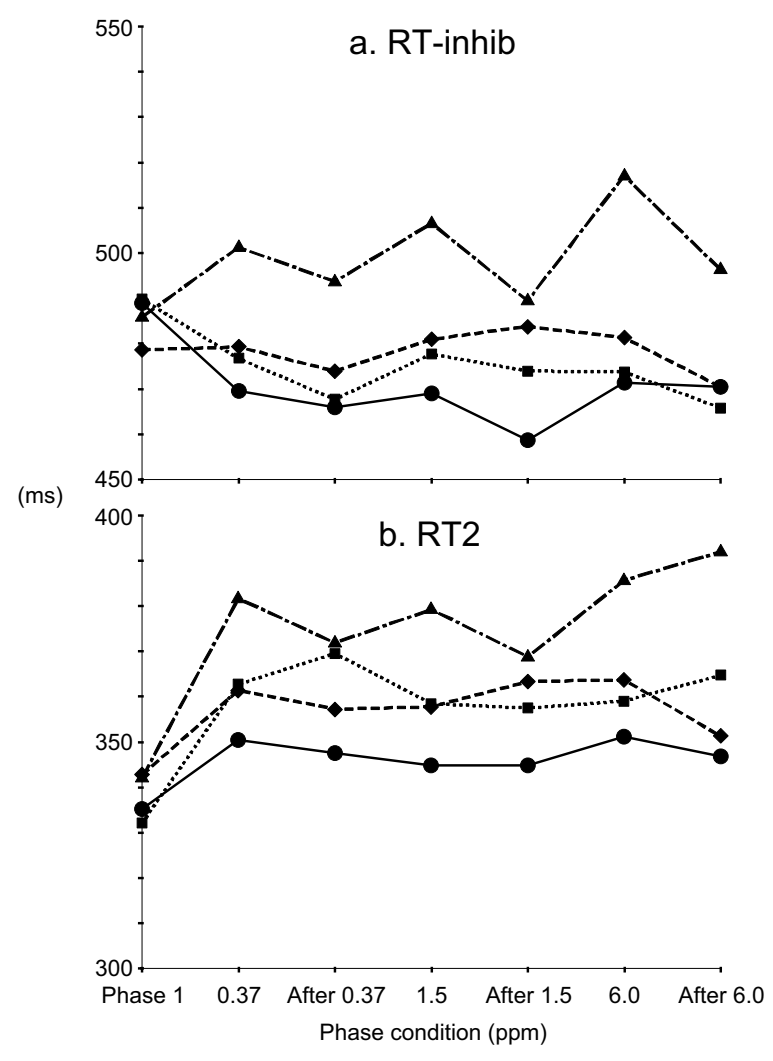

Figure 4. Reaction times (means) of the electrically annoyed (dotted line with squares), smell annoyed (broken line with diamonds), and generally annoyed (broken/dotted line with triangles) persons and the referents (solid line with circles) in the RT-inhib test (a) and RT2 test (b) during the first chamber phase, during 0.37-, 1.5-, and 6.0-ppm exposure to $n$-butyl acetate, and during each subsequent phase of 0 exposure. $(\mathrm{RT}$-inhib $=$ inhibition reaction-time test, $\mathrm{RT} 2$ = two-way reaction-time test) 
$\mathrm{P}=0.008$; post hoc for 0 ppm versus $6 \mathrm{ppm}$ : $9.4 \mathrm{~ms}, 95 \%$ CI 4.1-14.7, $\mathrm{P}=0.001$ ) (figure 4). A positive relationship was also found between cumulative exposure and RT2 reaction time $(\mathrm{P}=0.003$; beta $=0.14,95 \%$ CI 0.05 $0.23)$. The BuAc concentration was positively related to RT-inhib reaction time, but only for 6 ppm versus 0 ppm ( $\mathrm{P}=0.032$; post hoc: $11 \mathrm{~ms}, 95 \%$ CI 3-19, $\mathrm{P}=0.007)$. Finally, RT-inhib was also related to group $(\mathrm{P}=0.036)$, showing higher overall reaction times than for the reference group only in the GA group (post hoc: $36 \mathrm{~ms}$, $95 \%$ CI $11-62, \mathrm{P}=0.005)$. The error scores of the RTinhib test showed a floor effect (ie, were typically zero) across all groups and phases, and the data were not analyzed further.

\section{Discussion}

To summarize the results, only the GA group, with selfrated annoyance to both electrical equipment and smells or chemicals, showed widespread elevations in the annoyance ratings in response to the chemical provocation, comprising smell annoyance, fatigue, and mucous membrane irritation, when compared with the reference group. Moreover, only the GA group showed a pattern of sustained fatigue and mucous membrane irritation after each temporary cessation of the exposure. In addition, the GA group was the only group with a lower performance than the reference group in one of the neurobehavioral tests in response to the challenge. By comparison, only a few scattered deviations were observed in the two groups with self-reported high annoyance restricted either to smells or chemicals (SA group) or to electrical equipment (EA group).

Regarding the exposure-related determinants of challenge reactions, it was primarily the momentary BuAc concentration that affected the ratings and reaction-time performance, and the finding was general and not specific to the environmental annoyance groups. However, the impact of BuAc concentration on the smell annoyance ratings was stronger in all three annoyance groups than in the reference group, and a similarly stronger effect of BuAc concentration on the fatigue ratings was found for the EA and GA groups. Another exposure-related effect observed across the groups was a positive relationship between cumulative exposure and mucous membrane irritation, fatigue, and RT2 reaction time. It could not be demonstrated that a situational suggestion effect on the annoyance ratings and performance, induced by the chamber environment as such before the start of the chemical exposure, characterized the reactions of the annoyance groups. Only RT2 reaction time showed a slight increase after a participant entered the chamber, but the increase also occurred in the ref- erence group. This general effect on RT2 reaction time during the initial chamber phase has been observed in two previous challenge studies, and it is possibly due to slight tension among participants $(4,19)$.

Although suggestion effects among idiopathic environmental intolerance cases have previously been observed in a challenge study by Dalton \& Hummel (30), another challenge study of similar cases did not find significant suggestion effects (4). Our results suggest that among "generally annoyed" persons, a chemical odor is required as a perceptual "trigger" to initiate annoyance, which thereafter evolves rapidly (ie, within minutes) and persists to a considerable degree during intermittent breaks in exposure. This strong "off-on" reaction to the chemical odor seems to fit well into the "olfactory threshold model" suggested by Bolt \& Kiesswetter (18). The sustained annoyance after the cessation of exposure, found particularly in the GA group, also corresponds with the earlier observation made by Dalton et al (17), that a negative "cognitive bias" towards the exposure situation affected the ratings of irritation both during exposure to an odorant and after the cessation of exposure. The additional finding of slightly elevated smell intensity ratings in the EA, SA, and GA groups during intermittent phases without BuAc exposure may, in this context, be interpreted as hypervigilance towards, or "somatosensory amplification" (18) of, potential environmental threats as a common denominator for persons with different types of environmental intolerance. By contrast, no group difference was observed for the smell intensity ratings during exposure, a finding that corroborates several previous findings of a normal intensity perception of suprathreshold olfactory stimuli among smell-intolerant persons $(4,19$, 31, 32).

Whereas most previous chemical-challenge studies of idiopathic environmental intolerance have examined clinical cases, the participants of our study were nonpatients identified by five simple questions about recent annoyance to odors or electrical equipment. The application of this crude method still seems to have been successful in singling out persons with longstanding environmental annoyance, as shown by the elevated scores in the CGES questionnaire filled out prior to the challenge. Interestingly, the combination of self-reported annoyance attributed to both smells and electrical equipment (ie, by the GA group) in the initial five questions replied to 3 years previously was, in this study, associated with the highest CGES scores among the groups. These scores were not only high for the electrical and chemical sensitivity scales, but also for the two "general environmental sensitivity" scales covering sensitivity to a wide range of everyday stressors, including light, noise, and mental strain. This finding suggests that selfreported annoyance to several environmental factors 
may be the best predictor of high reactivity and widespread annoyance to any specific environmental factor, as shown in our study by the reactions of the GA group.

The limited reactivity to the chemical challenge observed in the SA group-restricted to higher smell annoyance ratings compared with those of the reference group - may indicate that a population sample with selfreported sensitivity restricted to smells has a relatively benign type of environmental intolerance, which is less likely to interfere with everyday life. Obviously, the SA group had a milder smell intolerance than the persons meeting the criteria for multiple chemical sensitivity, who, in previous studies, have shown pronounced annoyance in response to chemical challenge $(4,19,31)$. Since the possible presence of annoyance due to environmental triggers other than smells was not examined in these latter challenge studies, it remains unknown whether those with multiple chemical sensitivity in fact had a more widespread environmental annoyance similar to the GA group in our study. However, in view of our current findings and also those of others (7-9), it could be expected that they did. Presumably, people reporting reactions to a wide range of environmental triggers are more inclined to seek medical advice. It is therefore not surprising that subjective health complaints may lead to various diagnostic labels, such as "multiple chemical sensitivity", "electrical allergy", "chronic fatigue syndrome", and the like, depending on the medical specialty of the diagnostician and the context or illness belief system of the patient $(7,33)$.

Our study did not aim to assess the impact of neurotoxic versus sham exposures. It has been shown in previous double-blind, placebo-controlled challenge studies that people claiming hypersensitivity to chemicals and electromagnetic fields develop symptoms when appraising chemical exposure, whether actually exposed or not, but not when the exposure is masked. [See, eg, Andersson et al (2) and Dalton \& Hummel (30)]. The purpose of our study was, rather, to determine the relationship between self-reported environmental annoyance in everyday life and the reactions to various aspects of exposure to chemical odors. A wealth of data has documented the commonness of psychiatric disorders in idiopathic environmental intolerance, particularly somatoform, mood, and anxiety disorders, suggesting a constitutional mental vulnerability as one predisposing factor for the development of annoyance reactions attributed to the environment $(34,35)$. On the other hand, other data suggest that a large percentage of people with no previous history of emotional problems is at risk of developing idiopathic environmental intolerance-like conditions in the aftermath of extraordinarily stressful life events. For example, a substantial number of the military personnel deployed in the Persian Gulf War developed a sensitivity to chemical smells (36). The common denominator for running the risk of developing idiopathic environmental intolerance-like conditions seems to be emotional distress. In states of arousal, the human being has an enhanced vigilance for danger, is prone to act on simplistic beliefs and to revert to basic coping strategies such as avoidance, and has an enhanced susceptibility to conditioning processes, facilitating a spread of triggers (30, 37-39). Data suggest a high prevalence of milder variants of idiopathic environmental intolerance in the general population (40). In the final analysis, it may well turn out that the onset of environmental annoyance reactions is one of several signs of a long-term inability to cope successfully with the demands of life encountered in modern society.

\section{Acknowledgments}

This study was supported by the Swedish Council for Work Life Research, grant 2001-0322, and the Vårdal Foundation, grant A2001-044.

Thanks are due to psychologist Njördur Viborg for his skillful assistance in the collection of the data. We would like to thank Frida Carlsson for her administrative work and Berit Holmskov, Bengt Johansson, and Ulf Bergendorf for their assistance in the running and maintenance of the exposure chamber.

\section{References}

1. Wiesmuller GA, Ebel H, Hornberg C, Kwan O, Friel J. Are syndromes in environmental medicine variants of somatoform disorders? Med Hypotheses 2003;61(4):419-30.

2. Andersson B, Berg M, Arnetz BB, Melin L, Langlet I, Liden S. A cognitive-behavioral treatment of patients suffering from "electric hypersensitivity": subjective effects and reactions in a double-blind provocation study. J Occup Environ Med 1996;38(8):752-8.

3. Flodin U, Seneby A, Tegenfeldt C. Provocation of electric hypersensitivity under everyday conditions. Scand J Work Environ Health 2000;26(2):93-8.

4. Österberg K, Ørbæk P, Karlson B, Åkesson B, Bergendorf U. Annoyance and performance during the experimental chemical challenge of subjects with multiple chemical sensitivity. Scand J Work Environ Health 2003;29(1):40-50.

5. Report of multiple chemical sensitivities (MCS) workshop: International Programme on Chemical safety (IPCS)/German Workshop on Multiple Chemical Sensitivities. Int Arch Occup Environ Health 1997;69(6):224-6.

6. Ciccone DS, Natelson BH. Comorbid illness in women with chronic fatigue syndrome: a test of the single syndrome hypothesis. Psychosom Med 2003;65(2):268-75.

7. Aaron LA, Buchwald D. A review of the evidence for overlap among unexplained clinical conditions. Ann Intern Med 2001;134(9 Pt 2):868-81. 
8. Bell IR, Hardin EE, Baldwin CM, Schwartz GE. Increased limbic system symptomatology and sensitizability of young adults with chemical and noise sensitivities. Environ Res 1995;70:84-97.

9. Levallois P, Neutra R, Lee G, Hristova L. Study of selfreported hypersensitivity to electromagnetic fields in California. Environ Health Perspect 2002;110 suppl 4:619-23.

10. Lidén S. "Sensitivity to electricity"-a new environmental epidemic. Allergy 1996;51(8):519-24.

11. Ursin, H. Sensitization, somatization, and subjective health complaints. Int J Behav Med 1997;4(2):105-16.

12. Eriksen HR, Ursin H. Sensitization and subjective health complaints. Scand J Psychol 2002;43(2):189-96.

13. Arnetz BB. Model development and research vision for the future of multiple chemical sensitivity. Scand J Work Environ Health 1999;25(6):569-73.

14. McEwen BS, Stellar E. Stress and the individual: mechanisms leading to disease. Arch Intern Med 1993;153(18):2093-101.

15. Schulkin J, McEwen BS, Gold PW. Allostasis, amygdala, and anticipatory angst. Neurosci Biobehav Rev 1994;18(3):38596.

16. Bell IR, Baldwin CM, Schwartz GE. Sensitization studies in chemically intolerant individuals: implications for individual difference research. Ann N Y Acad Sci 2001;933:38-47.

17. Dalton P, Wysocki CJ, Brody MJ, Lawley HJ. The influence of cognitive bias on the perceived odor, irritation and health symptoms from chemical exposure. Int Arch Occup Environ Health 1997;69(6):407-17.

18. Bolt HM, Kiesswetter E. Is multiple chemical sensitivity a clinically defined entity? Toxicol Lett 2002;128(1-3):99-106.

19. Ørbæk P, Österberg K, Åkesson B, Bergendorf U, Karlson B, Seger L. Suprathreshold intensity and annoyance reactions in experimental challenge to toluene and n-butyl acetate among subjects with long-term solvent exposure. Scand J Work Environ Health 1998;24(5):432-8.

20. Österberg K, Ørbæk P, Karlson B, Seger L, Åkesson B, Bergendorf U. Psychological test performance during experimental challenge to toluene and n-butyl acetate in cases of solventinduced toxic encephalopathy. Scand J Work Environ Health 2000;26(3):219-26.

21. Östergren P-O, Merlo J, Lindström M, Rosvall M, Kahn FA, Lithman T. Hälsoförhållanden i Skåne: Folkhälsoenkät Skåne 2000 [Health conditions in Scania: Public health survey in Scania 2000]. Malmö (Sweden): Region Skåne, Kommunförbundet Skåne och Skåne läns allmänna försäkringskassa [County of Scania, the Scanian Association of Local Authorities, and the Scanian Regional Social Insurance Office]; 2001.

22. National Swedish Labour Board. NYK 82, Nordic Standard Classification of Occupations. Stockholm: National Swedish Labour Board; 1983.

23. Kiesswetter E, Sietmann B, Zupanic M, Van Thriel C, Golka K, Seeber A. Verhaltungstoxikologische Aspekte der Prävalens und Ätiologie "Multipler Chemischer Sensitivität" [Behavioral toxicological aspects of the prevalence and etiology of "multiple chemical sensitivity"]. Allergologie 1999;22:719-35.

24. Van Thriel C, Kiesswetter E, Blaszkewicz M, Golka K, Seeber A. Neurobehavioral effects during experimental exposure to 1-octanol and isopropanol. Scand J Work Environ Health 2003;29(2):143-51.

25. Wiesmuller GA, Van Thriel C, Steup A, Bachert C, Clinic EN, Blaszkewicz M, et al. Nasal function in self-reported chemically intolerant individuals. Arch Environ Health. 2002;57(3):247-54.

26. Cain WS. Testing olfaction in a clinical setting. Ear Nose Throat J 1989;68:316,322-8.

27. Winneke G. Structure and determinants of psychophysiological response to odorant/irritant air pollution. Ann N Y Acad Sci 1992;641:261-76.

28. Borg G. A category scale with ratio properties for intermodal and interindividual comparisons. In: Geissler HG, Petzold P, editors. Psychophysical judgment and the process of perception. Berlin: VEB Deutscher Verlag der Wissenschaften; 1982. p 25-33.

29. Levander S, Elithorn A. The automated psychological test system [manual]. Trondheim (Norway): Department of Psychiatry and Behavioral Medicine, University of Trondheim; 1987.

30. Dalton P, Hummel T. Chemosensory function and response in idiopathic environmental intolerance. Occup Med 2000;15(3):539-56.

31. Georgellis A, Lindelöf B, Lundin A, Arnetz B, Hillert L. Multiple chemical sensitivity in male painters: a controlled provocation study. Int J Hyg Environ Health 2003; 206(6):531-8.

32. Fernandez M, Schwartz GE, Bell IR. Subjective ratings of odorants by women with chemical sensitivity. Toxicol Ind Health 1999;15(6):577-81.

33. Barsky AJ, Borus JF. Functional somatic syndromes. Ann Intern Med 1999;130(11):910-21.

34. Black DW. The relationship of mental disorders and idiopathic environmental intolerance. Occup Med 2000;15(3):55770.

35. Hausteiner C, Bornschein S, Bickel H, Zilker T, Forstl H. Psychiatric morbidity and low self-attentiveness in patients with environmental illness. J Nerv Ment Dis 2003;191(1):505.

36. Proctor SP. Chemical sensitivity and gulf war veterans' illnesses. Occup Med 2000;15(3):587-99.

37. Guglielmi RS, Cox DJ, Spyker DA. Behavioral treatment of phobic avoidance in multiple chemical sensitivity. J Behav Ther Exp Psychiatry 1994;25(3):197-209.

38. Van den Bergh O, Devriese S, Winters W, Veulemans H, Nemery B, Eelen P, et al. Acquiring symptoms in response to odors: a learning perspective on multiple chemical sensitivity. Ann N Y Acad Sci 2001;933:278-90.

39. Devriese S, Winters W, Van Diest I, De Peuter S, Vos G, Van de Woestijne K, et al. Perceived relation between odors and a negative event determines learning of symptoms in response to chemicals. Int Arch Occup Environ Health 2004;77(3):2004.

40. Kreutzer R, Neutra RR, Lashuay N. Prevalence of people reporting sensitivities to chemicals in a population-based survey. Am J Epidemiol 1999;150(1):1-12.

Received for publication: 19 January 2004 